\title{
Predictors and outcomes of behavioral engagement in the context of text comprehension: when quantity means quality
}

\author{
Ivar Bråten ${ }^{1}(1) \cdot$ Natalia Latini $^{1} \cdot$ Ymkje E. Haverkamp $^{1}$
}

Accepted: 18 August 2021 / Published online: 1 September 2021

(c) The Author(s) 2021

\begin{abstract}
Using a path analytic approach with a sample of Norwegian undergraduate readers, we investigated the effects of behavioral engagement on text comprehension as reflected in students' post-reading written reports on the topic in question. Results indicated that the behavioral engagement components of writing time and the length of the written responses had distinctive, unique effects on comprehension performance, and that behavioral engagement also mediated the effects of cognitive (prior knowledge, working memory) and motivational (intrinsic reading motivation) individual differences on comprehension performance. Prior knowledge about the topic affected comprehension performance directly as well as indirectly through behavioral engagement. The results highlight the importance of behavioral engagement in the context of written comprehension assessment, and both theoretical and educational implications of these results are discussed.
\end{abstract}

Keywords Behavioral engagement · Text comprehension · Individual differences · Path analysis

\section{Introduction}

Students' engagement in academic learning tasks, or the lack of it, is a common concern among parents, educators, and researchers. Without engagement, students' individual cognitive and motivational resources can be considered inert, with limited influence on learning and performance. On the other hand, when these resources become operational through engagement in relevant learning tasks, students' real competencies may be revealed and even challenging tasks previously considered out of reach may be mastered. Accordingly, in this study, we built on

Ivar Bråten

ivar.braten@ped.uio.no

1 Department of Education, University of Oslo, Blindern, P.O. Box 1092, 0317 Oslo, Norway 
theoretical and empirical insights provided by recent educational research in assuming that students' individual cognitive and motivational resources would indirectly influence their performance through their persistence during task completion. As reading researchers, we were particularly interested in the task of comprehending informational text, which is essential for achievement and academic success (Shanahan, 2017), and in whether individual differences in both cognition and motivation would work through components of behavioral engagement in influencing students' comprehension performance. We therefore developed and tested a model in which differences in prior topic knowledge, working memory capacity, and intrinsic reading motivation indirectly affected students' performance through their time use and productive effort when engaging with the task. By moving behavioral engagement to center stage, this study also may have practical relevance because it can inform educators and policy makers about the need to take students' behavioral engagement into consideration when teaching and assessing text comprehension and developing curricula (Guthrie \& Klauda, 2016). Before we further specify the direct and indirect relationships between individual differences, components of behavioral engagement, and comprehension performance that we included in our hypothesized model, however, we describe the theoretical background of our study and prior relevant research in this area.

\section{Theoretical and empirical background}

\section{Conceptual clarification}

In academic contexts, engagement generally refers to the extent of students' active involvement and productive participation in learning activities (Ben-Eliyahu et al., 2018; Reeve, 2012). At the same time, academic engagement has been considered a multidimensional construct that may involve behavioral, affective, and cognitive dimensions (Ben-Eliyahu et al., 2018; Sinatra et al., 2015; Skinner et al., 2014), with behavioral engagement being the only dimension that figures in all conceptualizations of engagement (Olivier et al., 2020). Following Ben-Eliyahu et al. (2018), we conceptualize behavioral engagement as active, observable involvement in academic tasks, that is, as "what students involved in the learning activity would look like or be doing" (p. 88). More specifically, we define behavioral engagement as students' active, observable involvement in academic tasks as typified by time, effort, persistence, and productivity (Reeve, 2012; Sinatra et al., 2015; Skinner et al., 2014). Behavioral engagement in reading may thus be indicated by the time students invest in reading and reading assignments as well as the extent of their response to those assignments (Bråten et al., 2018; Guthrie \& Klauda, 2016). Because it refers to individual learners' engagement in particular tasks, our definition captures a person-oriented (rather than a context-oriented) grain size of behavioral engagement (Sinatra et al., 2015). According to Sinatra et al. (2015), the grain size of engagement measurement may vary on a continuum ranging from person-oriented, which focuses on individual learners and their task-related behavior, to context-oriented, which focuses on characteristics of the context (e.g., the classroom or school) that 
afford or constrain engagement. Moreover, our definition acknowledges that student behavioral engagement may have distinct components, such as time use and productivity, indicating that investigations of the antecedents and consequences of behavioral engagement could profitably focus on different behaviors separately (Olivier et al., 2020). Accordingly, in the current study, we focused on the behavior engagement components of writing time and the length of the written responses during a written comprehension task.

\section{Theoretical framework}

Within reading research, Guthrie and colleagues (e.g., Guthrie \& Alvermann, 1999; Guthrie et al., 1996, 2012; Guthrie \& Klauda, 2016; Guthrie \& Wigfield, 2000) have been leading proponents of the crucial role played by student engagement in performance and achievement. Thus, Guthrie and Wigfield (2000) presented the engagement model of reading development in which they linked both cognition and motivation to engagement in reading, such that engaged readers were conceived of as both knowledgeable in their construction of meaning from textual information and motivated to read in order to fulfill their goals and desires. It was not clear in that model, however, whether Guthrie and Wigfield distinguished between cognitive and motivational constructs on the one hand and engagement on the other, or whether cognitive and motivational constructs were considered inherent features of reading engagement.

In contrast, in the more recent heuristic model of predictors and outcomes of reading engagement proposed by Guthrie and Klauda (2016), reading engagement is clearly distinguished from its cognitive and motivational precursors, such as background knowledge with respect to cognition and intrinsic motivation with respect to motivation. Specifically, with a focus on the behavioral dimension of reading engagement, engagement is distinguished from motivation because the latter construct refers to internal processes energizing and guiding behavior whereas the former concerns the visible, overt expressions of motivation (see also, Eccles \& Wang, 2012). According to Guthrie and Klauda (2016), students are unlikely to invest much time and effort unless they have established a "cognitive system for reading," and motivation cannot be expected to translate into performance unless it is channeled into engagement in the reading task. In turn, behavioral engagement in reading is considered to exert a strong influence on reading performance and achievement, thus mediating distinctive, unique effects of individual differences in cognition and motivation on such outcome variables. It is thus a central tenet of this model that cognitive and motivational variables will influence behavioral engagement, as typified by time, effort, and persistence, which, in turn, will influence comprehension performance. While a range of cognitive and motivational variables are likely to influence behavioral engagement (Guthrie \& Klauda, 2016), prior knowledge and intrinsic motivation can be considered to play prominent roles in this regard. By assuming that these variables, at least in part, exert their influence on comprehension performance through behavioral engagement, behavioral engagement is brought to the forefront of reading psychology. 
In the current study, we built on Guthrie and Klauda's (2016) heuristic model and investigated whether student engagement in terms of time use and productivity would mediate the effects of individual cognitive (i.e., prior knowledge, working memory) and motivational (i.e., intrinsic reading motivation) resources on comprehension performance as assessed with a post-reading writing task. While the cognitive construct of prior knowledge and the motivational construct of intrinsic motivation were highlighted by Guthrie and Klauda (2016), several other theorists (e.g., Kintsch, 1998; van den Broek, 2010) have considered working memory important because it supports the construction of a coherent mental representation of text content by constituting a workspace for integrating textual information as well as textual information and related prior knowledge. More specifically, for coherence to be established, previously read information has to be held in working memory to allow its integration with incoming information, and information activated from prior knowledge has to be held in working memory to allow its integration with textual information (Kintsch, 1998). Working memory can therefore be regarded as an important component in a cognitive system for reading in the sense of Guthrie and Klauda (2016).

\section{Prior research}

Regarding direct effects of behavioral engagement on comprehension performance, several researchers have found that the time students invest in reading and comprehension tasks uniquely predicts their comprehension performance (Bråten et al., 2014, 2018; Du \& List, 2020; List, 2020; List et al., 2019). For example, Bråten et al. (2014), in a path analytic study with upper-secondary students, found that reading time predicted comprehension performance even when several individual differences (e.g., prior topic knowledge) and the use of deeper level comprehension strategies were controlled for. Likewise, Bråten et al. (2018), using hierarchical multiple regression analysis in a study of upper-secondary students, found that both the time used for reading the texts and the time used for completing the post-reading writing task used to measure comprehension contributed to performance over and above reading comprehension skills, topic knowledge, and topic interest. These findings were corroborated by List et al. (2019), who also used hierarchical multiple regression analysis to demonstrate that behavioral engagement in terms of the time undergraduate students devoted to text use uniquely predicted the quality of their post-reading written products. Moreover, List (2020), who performed structural equation modeling with undergraduate students, found that time on texts directly affected memory for textual information and integrated understanding when cognitive and motivational differences as well as deeper level strategy use were controlled for. Finally, Du and List (2020) found that both total reading time and total writing time were positively correlated with undergraduate students' comprehension performance as reflected in their post-reading written products.

Taken together, the results of these studies are consistent with the assumption that behavioral engagement in terms of the time used for processing text information and completing subsequent comprehension assessments has a direct positive 
effect on performance. A caveat is, however, that this positive effect may depend on the complexity of the task. Thus, as elegantly demonstrated by Goldhammer et al. (2014) in a large scale study, when adult readers work on reading literacy tasks that are easy and mainly require routine processing, time on task may actually be negatively related to performance. In contrast, when reading literacy tasks are more challenging and require controlled processing, time on task is likely a positive predictor of performance. Of note is that time on task as understood by Goldhammer et al. (2014) included all the time used from being presented with the reading task to having produced a response (i.e., completed the assessment).

Several researchers have also found that students' productivity when working on post-reading writing tasks used to measure comprehension performance may be positively related to performance (Bråten et al., 2018; Kammerer et al., 2021; Latini et al., 2019). Thus, Bråten et al. (2018) found that the length of undergraduate students' written products was a unique predictor of both content coverage and content integration in those products. Similarly, Kammerer et al. (2021) found that the length of students' written products was positively correlated with the quality of those products in terms of their content relevance. As a final example, Latini et al. (2019) found that when undergraduate students read two printed texts, the length of their written products mediated the effect of reading purpose (i.e., reading for exam vs. for pleasure) on the integrated understanding of those texts.

Of note is also that the length of students' written notes taken during reading, as an indication of their productivity, has been linked to the quality of their postreading comprehension performance, as reflected in their written products $(\mathrm{Du} \&$ List, 2020). Moreover, due to its documented relationship with the quality of written products, increased productivity has been considered a valuable outcome of integrated reading-writing interventions (e.g., De La Paz et al., 2017).

Several studies have also indicated that student engagement may mediate the effects of cognitive and motivational constructs on comprehension performance (for review, see Guthrie et al., 2012). In a study of early adolescent English learners, Taboada et al. (2013) showed that the effects of both general language proficiency and academic vocabulary on comprehension performance were mediated by engagement, and Wigfield et al. (2008) found that the effects of reading comprehension instruction on comprehension performance were mediated by engagement. Both these studies used a multidimensional measure of student engagement based on teacher ratings. Other work has linked both prior topic knowledge and interest, which is a construct closely related to intrinsic motivation (Schiefele et al., 2012), to comprehension performance via behavioral engagement, in particular (e.g., Bråten et al., 2014; Kammerer et al., 2021; List, 2020; List et al., 2019). For example, Bråten et al. (2014) found that both prior topic knowledge and interest in the topic were positively related to students' time use, with time use also mediating the effect of interest on their comprehension performance. Likewise, List (2020) found that behavioral engagement as indicated by time on task was affected by topic interest and thus mediated the effects of topic interest on comprehension performance, and List et al. (2019) found that the time students devoted to text use mediated the effects of situational (i.e., text-based) interest on the written comprehension products. Moreover, List (2020) found that a cognitive factor based on students' scores 
on a general, decontextualized measure of perceived strategy use predicted the time devoted to text use and, in turn, their comprehension performance. Both prior knowledge and topic interest were also positively related to indicators of behavioral engagement (e.g., number of unique websites visited and revisited) in the Kammerer et al. (2021) study.

With respect to working memory, the relationship between working memory and text comprehension is well established in the empirical literature (for reviews, see Follmer, 2018; Prat et al., 2016; Swanson \& Alloway, 2012). For example, in a metaanalysis including 26 studies examining relationships between working memory and comprehension performance, Follmer (2018) found an average correlation coefficient of $r=0.38$. Because working memory can be considered an important component in a cognitive system for reading by supporting the construction of a coherent mental representation of text content (Kintsch, 1998; van den Broek, 2010), students may be more likely to decrease their engagement in challenging comprehension tasks without sufficient working memory resources (Guthrie \& Klauda, 2016). Conversely, students with better working memory may be more willing to invest required time and effort in such tasks.

Both theoretical assumptions and empirical evidence thus suggest that the cognitive and motivational constructs of prior knowledge, working memory, and intrinsic motivation may indirectly affect comprehension performance via components of behavioral engagement, consistent with the theoretical framework proposed by Guthrie and Klauda (2016). Of note is, however, that the preliminary evidence is mainly derived from studies including time use (and not productivity) as an indicator of behavioral engagement. In addition to time use, we therefore included productivity as a potential mediator in our hypothesized model. Because we used a written comprehension task to measure students' text comprehension, we operationalized time use as the time used for producing the written response (i.e., writing time) and productivity as the length of the written response (i.e., number of words). As noted by Bråten et al. (2018), lack of engagement is often an issue when students are presented with such comprehension assessments, with students completing them in a quick and perfunctory way. This, in turn, may lead to a serious underestimation of students' comprehension skills. Following Bråten et al. (2018), we therefore assumed that writing time and response length would be valid indicators of behavioral engagement in the context of a written comprehension assessment. Crucial to our argument is the likelihood that, as a group, students who invest more time in the comprehension task and produce more text will perform better on that task. Of course, this is not inconsistent with the possibility that some students might perform well on the comprehension task without necessarily using much time or producing longer texts.

\section{The present study}

Given this theoretical and empirical background analysis, we developed the hypothesized model shown in Fig. 1 and tested the fit of this model to data collected from a sample of Norwegian undergraduates reading 10 paragraphs about the topic of 


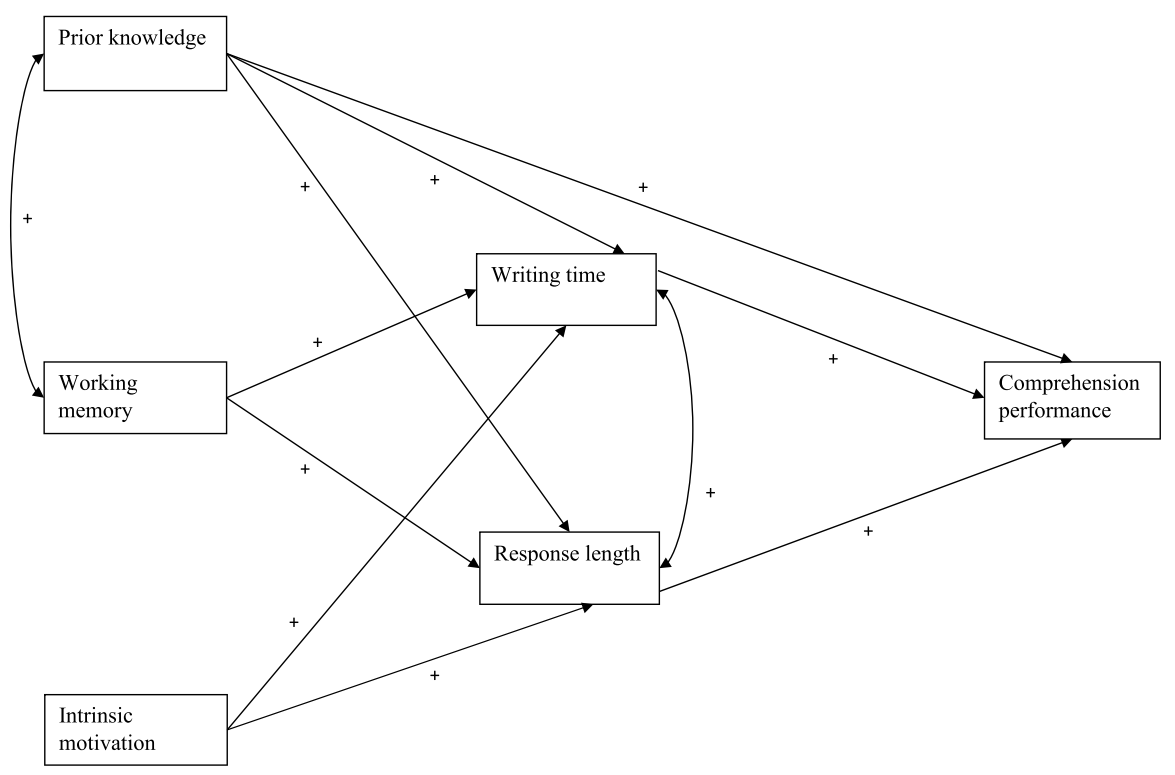

Fig. 1 The hypothesized model

phobias and subsequently writing a report on the topic without the text available. This is the first time a model that specifies direct and indirect relationships among the individual difference variables of prior topic knowledge, working memory, and intrinsic reading motivation, the behavioral engagement components of time use and productivity, and comprehension performance has been generated and tested to investigate these complex relationships collectively. The present study therefore represents a unique extension of prior research on the antecedents and consequences of reading engagement.

As can be seen in Fig. 1, both the time used for writing and the length of the written responses to the comprehension task were hypothesized to have direct positive effects on comprehension performance (Bråten et al., 2018; Du \& List, 2020; Kammerer et al., 2021; Latini et al., 2019). Our reason for expecting that these two behavioral engagement components, although related, were unique predictors of comprehension performance is that time may be used effectively for other relevant processes than producing text (e.g., planning or reflection), and that text may sometimes be produced efficiently without much time use. Of note is also that both these components of behavioral engagement were well aligned with the requirements of the challenging written comprehension task that we used in the present study (BenEliyahu et al., 2018; Goldhammer et al., 2014).

In turn, both components of behavioral engagement were hypothesized to be directly affected by the individual difference variables and, thus, to mediate the effects of those variables on comprehension performance (see Fig. 1). The direct positive effects of prior knowledge and intrinsic reading motivation on behavioral engagement are consistent with the heuristic model proposed by Guthrie and Klauda (2016), with these paths also supported by recent empirical work (Bråten et al., 
2014, 2018; Kammerer et al., 2021; List, 2020; List et al., 2020). With respect to working memory, this cognitive component figures prominently in several frameworks of text comprehension (Kintsch, 1998; McNamara \& Magliano, 2009; van den Broek, 2010), and its potential influence on behavioral engagement is consistent with Guthrie and Klauda (2016), who maintained that behavioral engagement is unlikely without basic cognitive system prerequisites. Presumably, the relevance of working memory increases when comprehension performance is assessed without the text available during responding (Andreassen \& Bråten, 2010), as in the present study.

In addition to its indirect effects on comprehension performance via the behavioral engagement components, we hypothesized that prior knowledge would have a direct positive effect on comprehension performance (Fig. 1). This hypothesis is consistent with prior research showing that prior knowledge may uniquely predict comprehension performance with a host of individual difference and processing variables, including behavioral engagement, controlled for (e.g., Bråten et al., 2014; Cromley \& Azevedo, 2007; Cromley et al., 2010; Taboada et al., 2009). Because all the hypothesized relationships in the model were expected to hold while controlling for the entire set of variables, we did not expect any direct effects of working memory and intrinsic motivation because it would be difficult for such direct effects to emerge when controlling for prior knowledge and the two behavioral engagement components.

Finally, we hypothesized that the cognitive individual difference variables of prior knowledge and working memory would be positively correlated (Swanson \& Alloway, 2012). The reason we did not hypothesize that prior knowledge and intrinsic reading motivation would be positively correlated is that we considered it likely that students might be fascinated by and intrinsically motivated to read about the particular topic (i.e., phobias) but still have quite superficial knowledge about it (Schunk et al., 2014). Also, we considered it likely that students might well have high levels of working memory capacity without being intrinsically motivated to read about the topic of phobia, and thus did not hypothesize any correlation between working memory and intrinsic reading motivation. Although we considered writing time and the length of the written responses to be distinct components of behavioral engagement with unique predictability for comprehension performance (see above), we expected the positive correlation between these two behavioral engagement components to be substantial.

\section{Method}

\section{Participants}

The sample consisted of 116 undergraduates in educational sciences and humanities at a large public university in southeast Norway. Most participants $(78.4 \%)$ were enrolled in the first year of a bachelor program, and $15.5 \%$ and $6.1 \%$, respectively, were enrolled in the second and third year. Their mean age was 21.95 years $(S D=2.88)$ and $77.6 \%$ were female. Most participants $(89 \%)$ had Norwegian as their 
first language, and the rest were bilingual. Participants in this study were included in a larger project on potential medium differences in text processing and comprehension. Thus, our participants also contributed to some of the data reported by Latini and Bråten (2021). However, hypotheses, measures, analyses, and findings included in this article are unique to this study.

We recruited participants in regular lectures and those who volunteered received a gift card worth NOK 200 (approx. USD 20) after the data collection. Collection and handling of all data met the requirements of the Personal Data Registers Act and were approved by the Norwegian Social Science Data Services.

\section{Materials}

\section{Text}

Each participant read one 10-paragraph informational text titled "Phobias," which was based on an encyclopedia on phobias (Milosevic \& McCabe, 2015) in addition to diverse popular science articles dealing with this topic. Both the length and the language of these original texts were adapted to form a single text consisting of 1000 words (approx. 100 words per paragraph). On a separate title page, source information (author's name and credentials plus venue and date of publication) was presented in addition to the title. The text was said to be authored by a female psychologist with a common Norwegian name and published in the Journal of the Norwegian Psychological Association in 2019.

The 10 paragraphs of the text were presented on 10 pages (one paragraph per page) and covered three main themes: (1) what phobias are, (2) why phobias occur, and (3) how phobias can be treated. The first theme was covered in the first four paragraphs, with the first paragraph describing fear as a natural response to real threats that can result in fight or flight reactions, the second paragraph discussing phobias in terms of irrational fear that interferes with everyday life, the third paragraph describing the main categories of phobias (i.e., social and specific phobias) and their characteristics, and the fourth paragraph describing and explaining some less familiar phobias (phonophobia and trypophobia). The second theme was covered in the next four paragraphs, with the fifth paragraph discussing genetic causes of phobia and relating them to autonomous nervous system vulnerability and lower levels of an inhibitory neurotransmitter, the sixth paragraph discussing how phobias can be learned through the mechanisms of classical conditioning and observational learning, the seventh paragraph discussing how phobias may have an evolutionary origin and be derived from fears that increased the chances of survival in the distant past, and the eighth paragraph discussing gender difference in the prevalence of phobias and the potential contribution of stereotypical gender roles in this regard. Finally, the third theme was covered in the last two paragraphs, with the ninth paragraph discussing medical treatment by means of sedative drugs or cortisol, and the tenth 
paragraph discussing psychological treatment in the form of traditional or virtual reality exposure therapy. ${ }^{1}$

We used Björnsson's, (1968) formula, based on word and sentence length, to compute the readability of the text. This resulted in an average readability estimate of $48.00(S D=9.99)$ for the 10 paragraphs, indicating that the difficulty level of the text was comparable to that of information texts from the Norwegian government (Vinje, 1982). This suggests that the text represented a sufficient challenge for our participants and, thus, was well suited for investigating the role of behavioral engagement in comprehension performance (Goldhammer et al., 2014).

\section{Prior knowledge}

We measured prior knowledge about phobias by asking participants to respond in writing to the following open ended questions: (1) what is a phobia?, (2) which types of phobias do you know?, (3) do you know why some people have phobias?, and (4) do you know how phobias can be treated? On the first question, scores were based on the definition of phobias by Milosevic and McCabe (2015), which included four aspects: (1) a phobia is a fear of something, (2) it is irrational, (3) it is intense and enduring, and (4) it is maladaptive. Participants were awarded one point if they included one of these aspects, two points if they included two of these aspects, and three points if they included three or four of these aspects. To receive a score of three on this question, participants had to include the aspect of irrationality, though. On the second question, one point was awarded if participants included one or more phobias from one of the following six categories, which commonly figure in the literature on phobias (Milosevic \& McCabe, 2015): (1) animals/insects, (2) nature (e.g., heights, water, darkness), (3) blood-injection-injury (e.g., needles, illness), (4) situations (e.g., flying, elevators, driving, small rooms), (5) social phobias, and (6) others. ${ }^{2}$ To receive two points, participants had to include phobias from two or three of these categories, and to receive three points, they had to include phobias from four or more categories. On the third question, one point was awarded for including one of the following potential causes of phobias: (1) genetics, (2) learning (including traumatic experiences), (3) evolutionary mechanisms, and (4) gender role stereotypes. To receive two points, participants had to include two of these potential causes, and to receive three points, they had to include three or four of them. Finally, on the fourth question, one point was awarded if participants included one of the three most common ways of treating phobias (i.e., exposure therapy, medication, and conversation based therapy). If participants included two or three of these

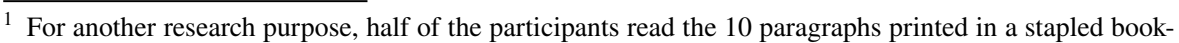
let and the other half read them in a PDF file on a tablet. Also, half of the participants were instructed to think aloud while reading whereas the other half were not. Because there were no effects of reading medium (digital vs. print), instruction (think aloud vs. no think aloud), or their interaction on any of the variables included in the present study, participants were collapsed into a single group for all statistical analyses in this study.

2 The first four of these categories fall in the broader category of specific phobias.
} 
treatments, two or three points were awarded. The possible range of scores was thus $0-3$ on each question and $0-12$ on the entire prior knowledge measure.

Two authors scored participants' responses to the four questions. A random selection of $25 \%$ of participants' responses was scored independently, resulting in a interrater reliability coefficient (Pearson's $r$ ) of 0.92 . Disagreements were solved in discussion. The authors scored half of the remaining participants' responses each.

\section{Working memory}

We used a Norwegian adaptation of Swanson and Trahan's (1992) Working Memory Span Task to measure working memory. This task was based on the technique developed by Daneman and Carpenter (1980), and the Norwegian adaptation has been validated in prior work with both secondary (Andresen et al., 2019) and postsecondary students (Delgado et al., 2020). The materials consisted of 42 unrelated declarative sentences, five to 12 words in length. These sentences were organized into 12 sets of sentences, with the number of sentences in each set increasing from two to five. The sentences in each set were read aloud to participants with an interval of two seconds between each sentence. Participants were asked to comprehend the sentences so that they could answer a question about the content of one of the sentences (which sentence was unknown in advance) as soon as the final sentence in the set was read. Also, on the same response form, they should write down the final word of each sentence in the set. An example of a three-sentence set is:

He has many pairs of shoes but none of them are blue.

The red balloon exploded when it hit the cactus.

The student was always late to the first lesson.

After listening to these sentences, participants were asked, "What color had the balloon?" They wrote down the answer to that question on the response form and afterwards wrote down the final word of each sentence on the same form. Thus, in accordance with current conceptualizations of working memory (e.g., Baddeley, 2001), this task required simultaneous processing and storage of information.

Following Friedman and Miyake (2005), the working memory task was scored by counting the total number of final words recalled across all 12 sets. Thus, the possible range of scores on this measure was $0-42$. However, to ensure that participants took the processing component of the task seriously and did not merely treat the task as one of verbal memory, points were awarded for correctly recalled final words only if the comprehension question for the set was answered correctly. ${ }^{3}$ Words were not counted as errors if spelled incorrectly and the order of the recalled words were not

\footnotetext{
3 As suggested by Conway et al. (2005), we also scored the working memory task by assigning credit to final words recalled despite errors made on the processing component of the task. The correlations between working memory and the other variables were very similar with this scoring procedure (e.g., the correlation with comprehension performance was 0.22 ), and when working memory scored according to this procedure was included in the path analysis, exactly the same direct and indirect relationships were statistically significant. However, the internal consistency reliability was somewhat lower (0.76 vs. 0.82$)$ when processing accuracy was not taken into account.
} 
taken into account (Conway et al., 2005). The internal consistency reliability (Cronbach's $\alpha$ ) for the 42 items (scored 1 or 0 ) was 0.82 .

\section{Intrinsic reading motivation}

A five-item inventory completed immediately after reading the text (and before writing the report) was used to measure participants' text-based intrinsic reading motivation. This measure has been validated in prior research with both grade-schoolers (Bråten et al., 2017) and undergraduates (Latini et al., 2020) and reflects a willingness to work with reading materials because it is experienced as exciting, interesting, and enjoyable in its own right (Deci \& Ryan, 2000; Schiefele et al., 2012). Thus, participants used a 5 -point scale $(1=$ does not fit at all, $5=$ fits very well $)$ to rate to what extent they had experienced the reading the text as exciting, interesting, fun, attractive, and enjoyable, respectively. Prior research has shown that such current (rather than habitual) intrinsic motivation, focusing on the willingness to engage in a specific reading task in a given situation, may be associated with engagement as well as with performance (Schiefele et al., 2012; Wigfield \& Cambria, 2010). The internal consistency reliability (Cronbach's $\alpha$ ) for participants' scores was 0.79 .

\section{Behavioral engagement}

Two components of behavioral engagement were measured in the present study: writing time and the length of the written reports used to assess comprehension performance (see below). To measure writing time, a stop watch was started when participants began writing, with the time for each participant registered as soon as they finished writing. To measure response length, we counted the number of words in each participant's post-reading written report using the word count tool included in Microsoft Word. It should be noted that participants were not explicitly informed that writing time was monitored or that the length of their written reports would be registered.

\section{Comprehension performance}

To measure comprehension of the text content, we asked participants to write a report in which they discussed what phobias are, why they occur, and how they are treated. In each of the 10 paragraphs, we identified the main idea and awarded participants 0 or 1 point dependent on whether this main idea was correctly represented in their written products or not. In addition, in each paragraph, we determined how the main idea was further elaborated and awarded participants 0 or 1 point dependent on whether this elaboration was present in their written products or not. For example, in the paragraph defining phobias (i.e., paragraph 2), we identified the main idea as phobias involve irrational fear and an elaboration of this idea as phobias interfere with adaptive functioning. The scores for each paragraph thus ranged from 0 to 2, and the scores on the entire measure could possibly range from 0 to 20 . Only the total scores were used in subsequent statistical analyses, with these reflecting the extent to which participants had represented an elaborated overview of the 
characteristics, causes, and treatments of phobias, as presented across the 10 paragraphs. The main idea and elaboration we identified in each of the 10 paragraphs as a basis for the scoring system are presented in Appendix 1.

Because students were asked to write their report without having the text available (see the Procedure section), performance on this measure could be assumed to be based on their mental representation of the text content. Of note is also that this measure of comprehension performance is different from our measures of behavior engagement because participants presumably may display good comprehension performance on this measure without necessarily using much time (i.e., efficiently) or many words (i.e., economically). Importantly, our comprehension measure can be considered to capture not only how students identified and represented the main idea in each paragraph but also how the main idea was further elaborated in that paragraph. Accordingly, high scores on this measure reflect students' identification, integration, and representation of the main ideas and their elaborations in the text.

Two authors scored the written responses. A random selection of $25 \%$ of participants' responses was scored independently, resulting in a high interrater reliability estimate (Cohen's Kappa =0.93). Also, the two raters' total scores for these participants were highly correlated (Pearson's $r=0.95, p<0.01$ ). All disagreements were solved in discussion, and the authors scored half of the remaining participants' responses each.

\section{Procedure}

The second author collected the data in individual 60-min sessions in a quiet room at the university. After participants had completed the working memory measure, which was administered orally, they received a folder containing a demographic survey and the prior knowledge measure and completed these materials in this order. Participants then read the following instruction:

You are now going to read a text about phobias in order to write a brief report in which you discuss what phobias are, why they occur, and how they are treated. The text consists of 10 paragraphs, with one paragraph on each page.

Moreover, participants were instructed that they could spend up to eight minutes reading the text. This time frame was based on piloting of the materials, which indicated that a time limit of eight minutes would allow all students to read the entire text. Immediately after participants had finished reading the text, they completed the inventory on intrinsic reading motivation. Finally, they accessed a web based questionnaire by clicking on a Google Chrome window located on the taskbar of a laptop computer. This questionnaire contained the following written task instruction:

Based on the text you just read, you are going to write a brief report in which you discuss what phobias are, why they occur, and how they are treated. You can spend as much time as you want on this writing task. It is important that you express yourself as completely and elaborately as you can. 
Table 1 Descriptive statistics for all variables

\begin{tabular}{lcccrr}
\hline & $M(S D)$ & Skewness $(S E)$ & Kurtosis $(S E)$ & Min & Max \\
\hline Prior knowledge & $5.50(1.54)$ & $0.13(0.23)$ & $0.90(0.45)$ & 2 & 11 \\
Working memory & $18.73(6.88)$ & $0.17(0.23)$ & $-0.46(0.45)$ & 5 & 35 \\
Intrinsic motivation & $4.13(0.65)$ & $-1.13(0.23)$ & $2.09(0.45)$ & 1.6 & 5 \\
Writing time (seconds) & $788.03(328.25)$ & $0.42(0.23)$ & $-0.81(0.45)$ & 166 & 1517 \\
Response length (words) & $289.66(124.83)$ & $0.86(0.23)$ & $0.45(0.45)$ & 82 & 648 \\
Comprehension performance & $7.48(3.02)$ & $0.39(0.23)$ & $-0.27(0.45)$ & 2 & 15 \\
\hline
\end{tabular}

Table 2 Zero-order correlations for all variables

\begin{tabular}{|c|c|c|c|c|c|c|}
\hline Variable & 1 & 2 & 3 & 4 & 5 & 6 \\
\hline 1. Prior knowledge & - & & & & & \\
\hline 2. Working memory & $.24 * *$ & - & & & & \\
\hline 3. Intrinsic motivation & .04 & -.01 & - & & & \\
\hline 4. Writing time (seconds) & .16 & $.25 * *$ & $.21 *$ & - & & \\
\hline 5. Response length (words) & $.25^{* *}$ & $.25 * *$ & $.21 *$ & $.69 * * *$ & - & \\
\hline 6. Comprehension performance & $.35 * * *$ & $.23^{*}$ & .12 & $.55 * * *$ & $.62 * * *$ & - \\
\hline
\end{tabular}

$* p<.05, * * p<.01, * * * p<.001$

Below this instruction, participants wrote their report in a separate text entry box with no word limit. The task instruction was visible during writing, but participants could not re-access the text. When finished, they submitted their report to a server by clicking on a "Send" button.

\section{Results}

Descriptive information about all measured variables are included in Table 1. This information indicates that the score distributions were approximately normal and, as such, could be used in parametric statistical analyses. Zero-order correlations between the variables are displayed in Table 2. All the individual difference and behavioral engagement variables, except intrinsic reading motivation, correlated positively and statistically significantly with comprehension performance. However, intrinsic reading motivation correlated positively and statistically significantly with both measures of behavioral engagement, as did working memory. Prior knowledge was statistically significantly correlated with the length of the written responses but not with writing time. Finally, although comprehension performance correlated substantially with the components of behavioral engagement, a shared variance of $30.3 \%$ between comprehension performance and writing time and a shared variance of $38.4 \%$ between comprehension performance and response length clearly indicate that these measures capture different constructs. 


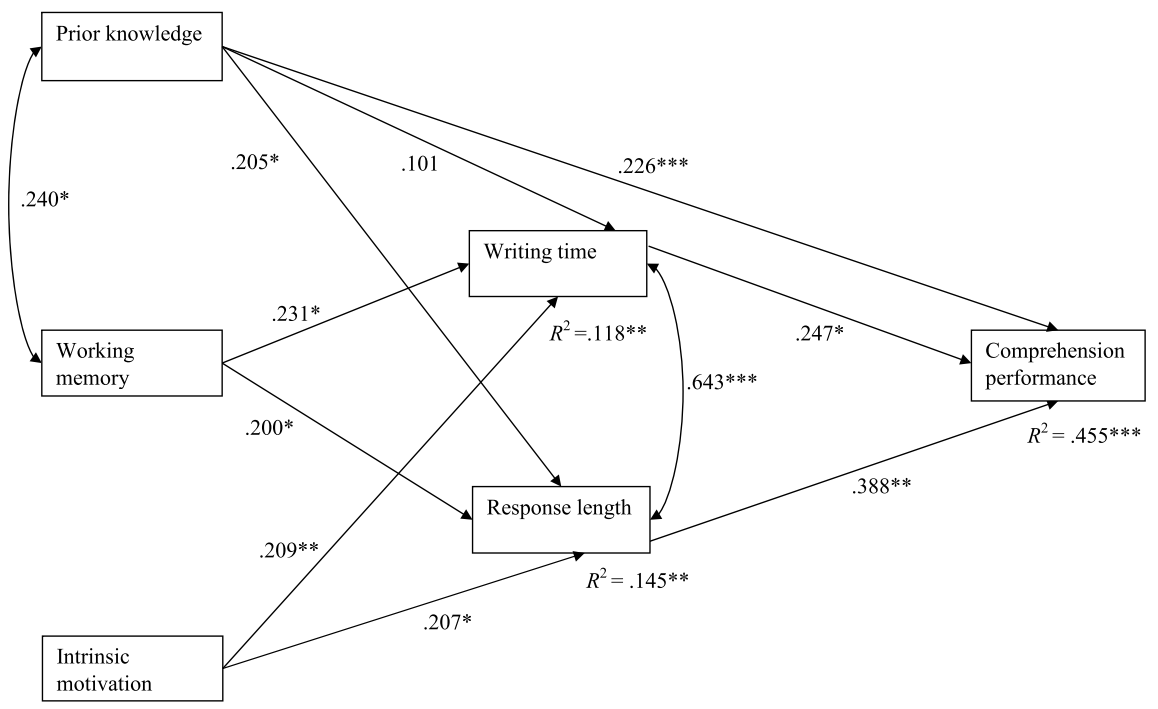

Fig. 2 The model with standardized path coefficients and explained variance of dependent variables. $* p<.05, * * p<.01, * * * p<.001$

The fit of the hypothesized model to the data was estimated with maximum likelihood path analysis using the lavaan $\mathrm{R}$ package ( $\mathrm{R}$ Core Team, 2020). According to common criteria for evaluating model fit (Hu \& Bentler, 1998, 1999; Marsh et al., 2004), the hypothesized model had an excellent fit to the data, with $\chi^{2}(4, n=116)=0.237, p=0.993$. The comparative fit index (CFI) was 1.000 ; the root mean square error of approximation (RMSEA) was $0.000,90 \%$ CI (0.000-0.000); and the standardized root mean residual (SRMR) was 0.008 . As can be seen in Fig. 2, eight of the nine causal paths and both correlations included in the hypothesized model (see Fig. 1) were statistically significantly different from zero and in the expected direction.

Specifically, there were direct effects of behavioral engagement on comprehension performance. As expected, the two components of behavioral engagement, despite their substantial intercorrelation $(r=0.643, p<0.001)$, had unique positive effects on performance, with $\beta=0.247, p=0.017$, for writing time, and $\beta=0.388, p=0.002$, for response length. In turn, the individual difference variables had direct effects on behavioral engagement. As expected, there were unique positive effects of all individual difference variables on response length, with $\beta=0.205, p=0.010$, for prior knowledge; $\beta=0.200, p=0.027$, for working memory; and $\beta=0.207, p=0.012$, for intrinsic reading motivation. With respect to writing time, working memory $(\beta=0.231, p=0.017)$ and intrinsic reading motivation $(\beta=0.209, p=0.004)$, but not prior knowledge $(\beta=0.099, p=0.237)$, had unique positive effects. However, as expected, prior knowledge also had a direct positive effect on comprehension performance, with $\beta=0.226, p<0.001$. Taken together, $11.8 \%(p=0.003)$ and $14.5 \%(p=0.001)$ of the variance in writing time and response length, respectively, were explained by the individual difference 
variables, both representing medium effect sizes according to Cohen's (1988) benchmarks.

Finally, both prior knowledge and intrinsic reading motivation had statistically significant mediated effects on comprehension performance via response length, with $\beta=0.080, p=0.034$, for prior knowledge, and $\beta=0.080, p=0.029$, for intrinsic motivation. The mediated effect of working memory on performance via response length was not statistically significant, however $(\beta=0.078, p=0.108)$. Moreover, none of the mediated effects of individual differences on performance via writing time reached a conventional level of statistical significance, with $\beta=0.024$, $p=0.321$, for prior knowledge; $\beta=0.057, p=0.078$, for working memory; and $\beta=0.051, p=0.063$, for intrinsic reading motivation. The model explained $45.5 \%$ $(p<0.001)$ of the variance in comprehension performance, which can be considered a large effect (Cohen, 1988).

\section{Discussion}

This study uniquely contributes to research on the role of behavioral engagement in comprehension performance. First, it investigated two different components of behavioral engagement, writing time and the length of the written response, as predictors of performance. Second, it included not only cognitive but also motivational constructs as potential contributors to those behavioral engagement components. Third, in addition to investigating direct relations between these sets of variables, we tested the effects of the cognitive and motivational constructs on comprehension performance as mediated by the two behavioral engagement components.

As expected, the two behavioral engagement components uniquely predicted students' comprehension performance as reflected in their post-reading written reports on the topic in question. While this is consistent with prior research indicating that behavioral engagement during written comprehension assessments may contribute to performance (Bråten et al., 2018; Du \& List, 2020; Kammerer et al., 2021; Latini et al., 2019), the unique predictability of the two behavioral engagement components provides new insights into the nature of active, observable involvement in the comprehension task. Thus, this finding indicates that an effective use of writing time involves relevant processes beyond text production, and that effective text production is not only a reflection of the time invested in writing. The predictability of these two behavioral engagement components is logical given their alignment with the demands of the written comprehension task. Still, we would argue that these findings are far from trivial given that students more often than not are required to demonstrate their comprehension by means of written products. We return to the theoretical and educational implications of these findings below.

Also as expected, the path analysis indicated that both cognitive and motivational constructs may underlie both behavioral engagement components, with prior knowledge, working memory, and intrinsic motivation uniquely predicting response length, and with two of these constructs (working memory and intrinsic motivation) uniquely predicting writing time. While the finding that behavioral engagement needs to be underpinned by both cognitive and motivational individual differences 
is consistent with prior empirical work (Bråten et al., 2014; Kammerer et al., 2021; List, 2020; List et al., 2019), our findings provide new insights by showing how prior knowledge, working memory, and intrinsic motivation may uniquely predict specific aspects of behavioral engagement in the context of written comprehension assessment. In regard to this, the finding that prior knowledge was more strongly related to response length than to writing time may indicate that students with higher levels of prior knowledge can produce relevant text more efficiently, without necessarily spending much time on the writing task. In contrast, some students with less prior knowledge might try to compensate for their lack of knowledge by spending more time on the task.

Although the individual difference variables had somewhat more restricted (i.e., fewer) indirect effects on comprehension performance than what we initially assumed, the finding that both prior knowledge and intrinsic motivation indirectly affected performance via response length was consistent with our hypotheses. Moreover, although not statistically significant, both working memory and intrinsic motivation showed clear trends toward the indirect effects of individual differences on performance via writing time that we hypothesized. Taken together, these findings suggest that both cognitive and motivational constructs may have mediated effects through behavioral engagement in the context of written comprehension assessment, in particular through the behavioral engagement component of response length.

Of note is that the indirect relationships that we did and did not find need to be interpreted in the multivariate context of our study, which means that they are controlled or adjusted by the other variables and relationships that we included in the model. Especially, because the two behavioral engagement components that we included were positively correlated, and because response length was a stronger predictor of comprehension performance than was writing time, no statistically significant indirect relationships emerged for writing time when adjusting for response length.

As hypothesized, beyond its mediated effect through behavioral engagement, prior knowledge had a direct effect on comprehension performance. This is consistent with prior research on the relationship between prior knowledge and text comprehension when other individual differences and processing variables are controlled for (e.g., Bråten et al., 2014; Cromley et al., 2010; Taboada et al., 2009), suggesting that students at higher levels of prior knowledge may display their comprehension through other means than using more time or writing longer texts, for example by the concepts they include and their argumentation (De La Paz \& McCutchen, 2017).

Our study provides clear support for the heuristic model of the antecedents and consequences of behavioral engagement proposed by Guthrie and Klauda (2016). Thus, in accordance with this model, behavioral engagement was found to contribute substantially to comprehension performance as measured by the writing task, as well as to mediate distinct, unique effects of both cognitive and motivational constructs on students' performance. These findings are also interpretable within the Interactive-Constructive-Active-Passive framework proposed by Chi and Wylie (2014). According to Chi and Wylie (2014), observable activities during a learning task may evoke cognitive processes with implications for students' learning outcomes. Specifically, compared to a more passive mode of behavioral 
engagement, a more active mode of behavioral engagement may thereby produce better learning outcomes. In this view, then, it seems likely that the behavioral engagement components that we targeted co-occurred with metacognitive and cognitive processing during the writing task (see also, Sinatra et al., 2015), such as processes of planning, mental text generation, reviewing, and revising (De La Paz \& McCutchen, 2017). That said, because prior research has indicated that behavioral engagement may contribute to comprehension performance even when deeper-level strategic text processing is controlled for (Bråten et al., 2014; List, 2020), it is conceivable that students' persistence in applying such strategies and performing the task may have an independent influence on performance. To further clarify this issue, it seems pertinent to include components of behavioral engagement together with measures of strategic processing taken during both reading and writing in the same study. So far, however, much more research on mediating processes in text comprehension has focused on cognitive (i.e., strategic) processing than on behavioral engagement (e.g., Cromley \& Azevedo, 2007; Cromley et al., 2010; Kopatich et al., 2019; Magliano et al., 2020), with the role of behavioral engagement still being an underfocused area within text comprehension research.

Our study comes with several limitations that may suggest avenues for further research. Among these is that, without further research, we cannot say that our findings are generalizable to other student populations, topics, and texts. In particular, although we did not include measures of reading and writing skills in this study, participants were undergraduate readers who volunteered to participate in a study on reading and, therefore, could be assumed to possess basic reading and writing skills. This, of course, makes it difficult to generalize our findings to other groups of readers, including younger and struggling readers. Especially struggling readers may have difficulties engaging in challenging literacy tasks such as those used in the current study, and it is an important issue for both researchers and educators to better understand individual and contextual factors associated with (dis)engagement among struggling readers, as well as how engagement may be assessed and promoted for such readers in the classroom.

Our study is also limited by the fact that the students read an experimental text and produced a report that did not have any real-world (i.e., academic) consequences for them. Future research should therefore try to investigate direct and mediating effects of behavioral engagement on comprehension performance when students work on ecologically more valid tasks that really matter in terms of academic performance.

Further, although the path analysis approach typically comes with causal terminology (e.g., direct and indirect effects), our ability to draw causal conclusions is limited by the fact that our study used a correlational rather than an experimental design. Our hypothesized model with its directional relationships had an excellent fit to the data, and these relationships were consistent with Guthrie and Klauda's (2016) theoretical framework as well as with prior research suggesting that behavioral engagement is a causal predictor of comprehension performance. Still, given the correlational nature of the data, we cannot be sure about the direction of effects or rule out the possibility of bidirectional relationships, especially between behavioral 
engagement and text comprehension. Thus, further experimental work is needed to clarify such issues concerning causality.

Finally, our study is inevitably limited by the individual differences we included in the model and the way we conceptualized and measured components of behavioral engagement and comprehension performance. Regarding individual differences, prior knowledge may be considered along multiple dimensions (i.e., with respect to amount, accuracy, specificity, and coherence; McCarthy \& McNamara, 2021) and, accordingly, be measured in more comprehensive ways. Further, other relevant types of executive functions (e.g., inhibition and flexibility; Follmer, 2018) may be included in addition to working memory in future studies. Also with respect to reading motivation, other relevant constructs, such as reading comprehension self-efficacy and reading comprehension task value (Bråten et al., 2013), may be studied as indirectly related to comprehension performance via behavioral engagement.

With respect to individual differences in reading, not only reading comprehension skills but also other literacy-related skills (e.g., vocabulary, metacognition, inference skills) could be included in future research on the antecedents of behavioral engagement in literacy tasks. Moreover, beyond cognitive and motivational individual differences, there may well be personality factors, such as need for cognition (Petty et al., 2009) and conscientiousness (Roberts et al., 2009), that contribute to students' behavioral engagement and therefore should be included in future research in this area (see, e.g., Bråten et al., 2014).

Regarding behavioral engagement, it may be argued that we measured this construct quite narrowly in this study. In particular, although writing time and response length could be considered especially relevant in the context of a written comprehension assessment, and although both turned out to be unique, positive predictors of performance, more information could probably be gained if behavioral engagement is measured during reading as well. For example, in addition to reading time, eye movement or navigation data might be collected to gauge students' behavioral engagement during reading. External observations of students' on and off task behaviors during both reading and writing may also be used (Fredricks \& McColskey, 2012). Preferably, future researchers in this area should use multiple methods of measuring behavioral engagement in order to cross-validate their findings.

Of course, our study is also limited by our particular approach to assessing text comprehension, focusing on students' ability to represent and communicate the main ideas and elaborations in an informational text on a relatively unfamiliar topic. This task proved quite challenging for the students, who obtained an average score of 7.48 out of 20 . However, other aspects of text comprehension, such as bridging and elaborative inferences (Magliano \& Millis, 2003), which may require other forms of engagement (e.g., deeper level strategic processing), were not targeted. Other measures of comprehension capturing such aspects should therefore be investigated in relation to student engagement in future research. It is also an open question to what extent students' writing skills may have influenced their comprehension performance in the present study. When future researchers in this area use written comprehension assessments, we therefore recommend that they try to measure writing skills independently and partial out their potential effects on comprehension performance. Alternatively, comprehension measures not requiring any writing could be used. 
Despite existing limitations, we sincerely believe that our findings may have educational implications by highlighting the crucial role of engagement in literacy tasks, as well as the challenges this poses for literacy educators ( $\mathrm{Ng} \&$ Graham, 2018). As noted by other researchers (e.g., Afflerbach \& Harrison, 2017; Guthrie \& Klauda, 2016), students' engagement in literacy tasks may be promoted by classroom practices and contexts that provide meaningful choices among texts to read and tasks to perform, that provide relevance by connecting texts and tasks to real world activities and students' lived experiences, and that organize active, goal-directed collaboration among students to infuse enjoyment and excitement into the meaning making process. Such research-based recommendations are consistent with our findings that intrinsic reading motivation may underlie important components of behavioral engagement. However, consistent with our findings, not only intrinsic motivation but also students' prior knowledge may underlie their engagement in literacy tasks. It is therefore important that educators try to ensure that students possess sufficient prior knowledge for engagement to occur, for example by introducing reading tasks through pre-reading hands-on activities or activation of relevant background knowledge and experiences in a social setting (e.g., a class discussion; Bråten et al., 2017). Finally, regarding working memory, our findings seem to suggest that students should work with literacy tasks adapted to their working memory capacities, such that students at lower levels of working memory are not further hindered in their literacy development by losing their engagement in such tasks.

\section{Appendix 1}

Main idea and elaboration in each text paragraph

\section{Paragraph 1}

Main idea: Fear is a natural reaction to danger.

Elaboration: A fear reaction can involve either fight or flight.

\section{Paragraph 2}

Main idea: Phobias involve rational fear.

Elaboration: Phobias interfere with adaptive functioning.

\section{Paragraph 3}

Main idea; The main types of phobias are social phobias and specific phobias.

Elaboration: Description of both social and specific phobias and mentioning at least one category of specific phobias. 


\section{Paragraph 4}

Main idea: Some less familiar phobias are phonophobia and trypophobia. Elaboration: Description of both phonophobia and trypophobia.

\section{Paragraph 5}

Main idea: Phobias may have genetic causes.

Elaboration: The genetic explanation is related to the (autonomous) nervous system/a chemical substance in the brain/GABA.

\section{Paragraph 6}

Main idea: Phobias may be learned.

Elaboration: Learning of phobias may occur by means of classical conditioning and by means of observational learning (at least one form must be explained).

\section{Paragraph 7}

Main idea: Phobias may be caused by an innate tendency to fear things that were dangerous in the distant past (i.e., have an evolutionary origin).

Elaboration: Fear enhanced our chances of survival.

\section{Paragraph 8}

Main idea: Phobias are more common among women than among men.

Elaboration: This may be associated with typical gender role patterns, with boys confronting dangers and girls avoiding dangers and/or being better at identifying emotional states in others.

\section{Paragraph 9}

Main idea: Phobias may be treated with medicines.

Elaboration: These medicines are anxiety reducing and/or cortisol (i.e., a stress hormone that inhibits another stress hormone, adrenaline).

\section{Paragraph 10}

Main idea: Phobias may be treated with exposure therapy. 


\title{
Elaboration: Exposure therapy involves gradually exposing persons to what they fear in a safe environment.
}

\author{
Funding Open access funding provided by University of Oslo (incl Oslo University Hospital).
}

Open Access This article is licensed under a Creative Commons Attribution 4.0 International License, which permits use, sharing, adaptation, distribution and reproduction in any medium or format, as long as you give appropriate credit to the original author(s) and the source, provide a link to the Creative Commons licence, and indicate if changes were made. The images or other third party material in this article are included in the article's Creative Commons licence, unless indicated otherwise in a credit line to the material. If material is not included in the article's Creative Commons licence and your intended use is not permitted by statutory regulation or exceeds the permitted use, you will need to obtain permission directly from the copyright holder. To view a copy of this licence, visit http://creativecommons.org/licen ses/by/4.0/.

\section{References}

Afflerbach, P., \& Harrison, C. (2017). What is engagement, how is it different from motivation, and how can I promote it? Journal of Adolescent and Adult Literacy, 61(2), 217-220. https://doi.org/10.1002/ jaal.679

Andreassen, R., \& Bråten, I. (2010). Examining the prediction of reading comprehension on different multiple-choice tests. Journal of Research in Reading, 33(3), 263-283. https://doi.org/10.1111/j. 1467-9817.2009.01413.x

Andresen, A., Anmarkrud, Ø., \& Bråten, I. (2019). Investigating multiple source use among students with and without dyslexia. Reading and Writing: An Interdisciplinary Journal, 32(5), 1149-1174. https:// doi.org/10.1007/s11145-020-10030-8

Baddeley, A. D. (2001). Is working memory still working? The American Psychologist, 56(11), 851-864. https://doi.org/10.1037/0003-066X.56.11.851

Ben-Eliyahu, A., Moore, D., Dorph, R., \& Schunn, C. D. (2018). Investigating the multidimensionality of engagement: Affective, behavioral, and cognitive engagement across science activities and contexts. Contemporary Educational Psychology, 53, 87-105. https://doi.org/10.1016/j.cedpsych.2018. 01.002

Björnsson, C. -H. (1968). Läsbarhet [Readability]. Liber.

Bråten, I., Anmarkrud, Ø., Brandmo, C., \& Strømsø, H. I. (2014). Developing and testing a model of direct and indirect relationships between individual differences, processing, and multiple-text comprehension. Learning and Instruction, 30, 9-24. https://doi.org/10.1016/j.learninstruc.2013.11.002

Bråten, I., Brante, E. W., \& Strømsø, H. I. (2018). What really matters: The role of behavioural engagement in multiple document literacy tasks. Journal of Research in Reading, 41(4), 680-699. https:// doi.org/10.1111/1467-9817.12247

Bråten, I., Ferguson, L. E., Anmarkrud, Ø., \& Strømsø, H. I. (2013). Prediction of learning and comprehension when adolescents read multiple texts: The roles of word-level processing, strategic approach, and reading motivation. Reading and Writing: An Interdisciplinary Journal, 26(3), 321348. https://doi.org/10.1007/s11145-012-9371-x

Bråten, I., Johansen, R.-P., \& Strøms $\varnothing$, H. I. (2017). Effects of different ways of introducing a reading task on intrinsic motivation and comprehension. Journal of Research in Reading, 40(1), 17-36. https://doi.org/10.1111/1467-9817.12053

Chi, M. T. H., \& Wylie, R. (2014). The ICAP framework: Linking cognitive engagement to active learning outcomes. Educational Psychologist, 49(4), 219-243. https://doi.org/10.1080/00461520.2014. 965823

Cohen, J. (1988). Statistical power analysis for the behavioral sciences (2nd ed.). Erlbaum.

Conway, A. R. A., Kane, M. J., Bunting, M. F., Hambrick, D. Z., Wilhelm, O., \& Engle, R. W. (2005). Working memory span tasks: A methodological review and user's guide. Psychonomic Bulletin \& Review, 12(5), 769-786. https://doi.org/10.3758/BF03196772 
Cromley, J. G., \& Azevedo, R. (2007). Testing and refining the direct and inferential mediation model of reading comprehension. Journal of Educational Psychology, 99(2), 311-332. https://doi.org/10. 1037/0022-0663.99.2.311

Cromley, J. G., Snyder-Hogan, L. E., \& Luciw-Dubas, U. A. (2010). Reading comprehension of scientific text: A domain-specific test of the direct and inferential mediation model of reading comprehension. Journal of Educational Psychology, 102(3), 687-700. https://doi.org/10.1037/a0019452

Daneman, M., \& Carpenter, P. A. (1980). Individual differences in working memory and reading. Journal of Verbal Learning and Verbal Behavior, 19(4), 450-466. https://doi.org/10.1016/S0022-5371(80) 90312-6

De La Paz, S., \& McCutchen, D. (2017). Learning to write. In R. E. Mayer \& P. A. Alexander (Eds.), Handbook of research on learning and instruction (2nd ed., pp. 33-56). Routledge.

De La Paz, S., Monte-Sano, C., Felton, M., Croninger, R., Jackson, C., \& Piantedosi, K. W. (2017). A historical writing apprenticeship for adolescents: Integrating disciplinary learning with cognitive strategies. Reading Research Quarterly, 52(1), 31-52. https://doi.org/10.1002/rrq.147

Deci, E. L., \& Ryan, R. M. (2000). The "what" and "why" of goal pursuits: Human needs and the selfdetermination of behavior. Psychological Inquiry, 11(4), 227-268. https://doi.org/10.1207/S1532 7965PLI1104_01

Delgado, P., Stang Lund, E., Salmerón, L., \& Bråten, I. (2020). To click or not to click: Investigating conflict detection and sourcing in a multiple document hypertext environment. Reading and Writing: An Interdisciplinary Journal, 33(8), 2049-2072. https://doi.org/10.1007/s11145-020-10030-8

Du, H., \& List, A. (2020). Researching and writing based on multiple texts. Learning and Instruction, 66, 101297. https://doi.org/10.1016/j.learninstruc.2019.101297

Eccles, J., \& Wang, M. (2012). Part I commentary: So what is student engagement anyway? In S. L. Christenson, A. L. Reschly, \& C. Wylie (Eds.), Handbook of research on student engagement (pp. 133-145). Springer.

Follmer, D. J. (2018). Executive function and reading comprehension: A meta-analytic review. Educational Psychologist, 53(1), 2-60. https://doi.org/10.1080/00461520.2017.1309295

Fredricks, J. A., \& McColskey, W. (2012). The measurement of student engagement: A comparative analysis of various methods and student self-report instruments. In S. L. Christenson, A. L. Reschly, \& C. Wylie (Eds.), Handbook of research on student engagement (pp. 763-782). Springer.

Friedman, N. P., \& Miyake, A. (2005). Comparison of four scoring methods for the reading span test. Behavior Research Methods, 37(4), 581-590. https://doi.org/10.3758/BF03192728

Goldhammer, F., Naumann, J., Stelter, A., Tóth, K., Rölke, H., \& Klieme, E. (2014). The time on task effect in reading and problem solving is moderated by task difficulty and skill: Insights from a computer-based large-scale assessment. Journal of Educational Psychology, 106(3), 608-626. https:// doi.org/10.1037/a0034716

Guthrie, J. T., \& Alvermann, D. A. (Eds.). (1999). Engaged reading: Processes, practices, and policy implications. Teachers College Press.

Guthrie, J. T., \& Klauda, S. L. (2016). Engagement and motivation processes in reading. In P. Afflerbach (Ed.), Handbook of individual differences in reading: Reader, text, and context (pp. 41-53). Routledge.

Guthrie, J. T., McGough, K., Bennett, L., \& Rice, M. E. (1996). Concept-oriented reading instruction: An integrated curriculum to develop motivation and strategies for reading. In L. Baker, P. Afflerbach, \& D. Reinking (Eds.), Developing engaged readers in school and home communities (pp. 165-190). Erlbaum.

Guthrie, J. T., \& Wigfield, A. (2000). Engagement and motivation in reading. In M. L. Kamil, P. B. Mosenthal, P. D. Pearson, \& R. Barr (Eds.), Handbook of reading research (Vol. 3, pp. 403-422). Erlbaum.

Guthrie, J. T., Wigfield, A., \& You, W. (2012). Instructional contexts for engagement and achievement in reading. In S. L. Christenson, A. L. Reschly, \& C. Wylie (Eds.), Handbook of research on student engagement (pp. 601-634). Springer.

Hu, L. T., \& Bentler, P. M. (1998). Fit indices in covariance structure modeling: Sensitivity to underparameterized model misspecification. Psychological Methods, 3(4), 424-453. https://doi.org/10. 1037/1082-989X.3.4.424

Hu, L. T., \& Bentler, P. M. (1999). Cutoff criteria for fit indexes in covariance structure analysis: Conventional criteria versus new alternatives. Structural Equation Modeling, 6(1), 1-55. https://doi.org/10. 1080/10705519909540118 
Kammerer, Y., Gottschling, S., \& Bråten, I. (2021). The role of Internet-specific justification beliefs in source evaluation and corroboration during Web search on an unsettled socio-scientific issue. Journal of Educational Computing Research, 59(2), 342-378. https://doi.org/10.1177/0735633120 952731

Kintsch, W. (1998). Comprehension: A paradigm for cognition. Cambridge University Press.

Kopatich, R. D., Magliano, J. P., Millis, K. K., Parker, C. P., \& Ray, M. (2019). Understanding how language-specific and domain-general resources support comprehension. Discourse Processes, 56(7), 530-552. https://doi.org/10.1080/0163853X.2018.1519358

Latini, N., \& Bråten, I. (2021). Strategic text processing across mediums: A verbal protocol study. Reading Research Quarterly. https://doi.org/10.1002/rrq.418.

Latini, N., Bråten, I., Anmarkrud, Ø., \& Salmerón, L. (2019). Investigating effects of reading medium and reading purpose on behavioral engagement and textual integration in a multiple document context. Contemporary Educational Psychology, 59, 101797. https://doi.org/10.1016/j.cedpsych.2019. 101797.

Latini, N., Bråten, I., \& Salmerón, L. (2020). Does reading medium affect processing and integration of textual and pictorial information? A multimedia eye-tracking study. Contemporary Educational Psychology, 62, 101870. https://doi.org/10.1016/j.cedpsych.2020.101870.

List, A. (2020). Investigating the cognitive affective engagement model of learning from multiple texts: A structural equation modeling approach. Reading Research Quarterly. https://doi.org/10.1002/rrq. 361

List, A., Stephens, L. A., \& Alexander, P. A. (2019). Examining interest throughout multiple text use. Reading and Writing: An Interdisciplinary Journal, 32(2), 307-333. https://doi.org/10.1007/ s11145-020-10041-5

Magliano, J. P., Higgs, K., Santuzzi, A., Tonks, S. M., O’Reilly, T., Sabatini, J., Feller, D., Kopatich, R. D., Ray, M., \& Parker, C. (2020). Testing the inference mediation hypothesis in a post-secondary context. Contemporary Educational Psychology, 61, 101867. https://doi.org/10.1016/j.cedpsych. 2020.101867

Magliano, J. P., \& Millis, K. K. (2003). Assessing reading skill with a think-aloud procedure and latent semantic analysis. Cognition and Instruction, 21(3), 251-283. https://doi.org/10.1207/S1532690XC I2103_02

Marsh, H. W., Hau, K. T., \& Wen, Z. (2004). In search of golden rules: Comment on hypothesis testing approaches to setting cutoff values for fit indexes and dangers in overgeneralizing Hu and Bentler's (1999) findings. Structural Equation Modeling, 11(3), 320-341. https://doi.org/10.1207/s15328007s em1103_2

McCarthy, K. S., \& McNamara, D. S. (2021). The multidimensional knowledge in text comprehension framework. Educational Psychologist. https://doi.org/10.1080/00461520.2021.1872379

McNamara, D. S., \& Magliano, J. P. (2009). Toward a comprehensive model of comprehension. Psychology of Learning and Motivation, 51, 297-384. https://doi.org/10.1016/S0079-7421(09)51009-2

Milosevic, I., \& McCabe, R. E. (Eds.). (2015). Phobias: The psychology of irrational fear. ABC-CLIO LLC.

$\mathrm{Ng}, \mathrm{C}$. , \& Graham, S. (2018). Improving literacy engagement: Enablers, challenges and catering for students from disadvantaged backgrounds. Journal of Research in Reading, 41(4), 615-624. https:// doi.org/10.1111/1467-9817.12252

Olivier, E., Galand, B., Hospel, V., \& Dellisse, S. (2020). Understanding behavioural engagement and achievement: The roles of teaching practices and student sense of competence and task value. British Journal of Educational Psychology, 90(4), 887-909. https://doi.org/10.1111/bjep.12342

Petty, R. E., Briñol, P., Loersch, C., \& McCaslin, M. J. (2009). The need for cognition. In M. R. Leary \& R. H. Hoyle (Eds.), Handbook of individual differences in social behavior (pp. 318-329). Guilford.

Prat, C. S., Seo, R., \& Yamasaki, B. L. (2016). The role of individual differences in working memory capacity on reading comprehension ability. In P. Afflerbach (Ed.), Handbook of individual differences in reading: Reader, text, and context (pp. 331-347). Routledge.

R Core Team. (2020). R: A language and environment for statistical computing. R Foundation for Statistical Computing.

Reeve, J. (2012). A self-determination theory perspective on student engagement. In S. Christensen, A. Reschly, \& C. Wylie (Eds.), Handbook of research on student engagement (pp. 149-173). Springer.

Roberts, B. W., Jackson, J. J., Fayard, J. V., Edmonds, G., \& Meints, J. (2009). Conscientiousness. In M. R. Leary \& R. H. Hoyle (Eds.), Handbook of individual differences in social behavior (pp. 369381). Guilford. 
Schiefele, U., Schaffner, E., Möller, J., \& Wigfield, A. (2012). Dimensions of reading motivation and their relation to reading behavior and competence. Reading Research Quarterly, 47(4), 427-463. https://doi.org/10.1002/RRQ.030

Schunk, D. H., Meece, J. L., \& Pintrich, P. R. (2014). Motivation in education: Theory, research, and applications (4th ed.). Pearson Merrill Prentice Hall.

Shanahan, C. (2017). Comprehension in the disciplines. In S. E. Israel (Ed.), Handbook of research on reading comprehension (2nd ed., pp. 479-499). Guilford.

Sinatra, G. M., Heddy, B. C., \& Lombardi, D. (2015). The challenges of defining and measuring student engagement in science. Educational Psychologist, 50(1), 1-13. https://doi.org/10.1080/00461520. 2014.1002924

Skinner, E., Pitzer, J., \& Brule, H. (2014). The role of emotion in engagement, coping, and the development of motivational resilience. In R. Pekrun \& L. Linnenbrink-Garcia (Eds.), International Handbook of Emotions in Education (pp. 331-347). Routledge.

Swanson, H. L., \& Alloway, T. P. (2012). Working memory, learning, and academic achievement. Theories, constructs, and critical issuesIn K. R. Harris, S. Graham, \& T. Urdan (Eds.), APA educational psychology handbook (Vol. 1, pp. 327-366). American Psychological Association.

Swanson, H. L., \& Trahan, M. F. (1992). Learning disabled readers' comprehension of computer mediated text: The influence of working memory, metacognition, and attribution. Learning Disabilities Research and Practice, 7(2), 74-86.

Taboada, A., Tonks, S. M., Wigfield, A., \& Guthrie, J. T. (2009). Effects of motivational and cognitive variables on reading comprehension. Reading and Writing: An Interdisciplinary Journal, 22(1), 85-106. https://doi.org/10.1007/s11145-008-9133-y

Taboada, A., Townsend, D., \& Boynton, M. J. (2013). Mediating effects of reading engagement on the reading comprehension of early adolescent English language learners. Reading \& Writing Quarterly, 29(4), 309-332. https://doi.org/10.1080/10573569.2013.741959

van den Broek, P. (2010). Using texts in science education: Cognitive processes and knowledge representation. Science, 328(5977), 453-456. https://doi.org/10.1126/science.1182594

Vinje, F. E. (1982). Journalistspråket [The journalist language]. Institute for Journalism.

Wigfield, A., \& Cambria, J. (2010). Students' achievement values, goal orientations, and interest: Definitions, development, and relations to achievement outcomes. Developmental Review, 30(1), 1-35. https://doi.org/10.1016/j.dr.2009.12.001

Wigfield, A., Guthrie, J. T., Perencevich, K. C., Taboada, A., Klauda, S. L., McRae, A., \& Barbosa, P. (2008). Role of reading engagement in mediating effects of reading comprehension instruction on reading outcomes. Psychology in the Schools, 45(5), 432-445. https://doi.org/10.1002/pits.20307

Publisher's Note Springer Nature remains neutral with regard to jurisdictional claims in published maps and institutional affiliations. 